\title{
TOPICAL APPLICATION OF THE PALM TOCOTRIENOL-RICH FRACTION (TRF) ENHANCES CUTANEOUS WOUND HEALING IN TYPE 2 DIABETIC MICE
}

\section{ZAIZUHANA SHAHRIM ${ }^{1,2 *}$; SUZANA MAKPOL ${ }^{2}$; GEOK CHIN TAN; NURUL AISHAH MUHAMMAD' and ZAFARIZAL ALDRIN AZIZUL HASAN ${ }^{1}$}

\begin{abstract}
Type 2 diabetic (T2D) wounds are characterised by excessive, persistent inflammation and oxidative stress, resulting in delayed healing. The tocotrienol-rich fraction (TRF) has potential as a therapeutic agent in improving diabetic wounds due to its anti-inflammatory and antioxidative effects. Thus, we aimed to evaluate the effect of the TRF on diabetic cutaneous wounds using a T2D mouse model. Full-thickness wounds were made on the backs of mice, and the TRF formulation was topically applied. The effect of the TRF was evaluated by examining wound closure, histology, CD31 immunohistochemistry and collagen deposition with Masson's trichrome staining. Biochemical assessments of catalase (CAT), glutathione peroxidase (GPx), myeloperoxidase (MPO), protein levels, transforming growth factor beta-1 (TGF- $\beta 1)$, metalloproteinase-9 (MMP-9) and cytokine production were performed. The results showed that TRF treatment enhanced wound closure and healing in the T2D mouse wounds. The TRF increased CAT, GPx, protein, hydroxyproline and TGF- $\beta 1$ levels but reduced MPO activity and MMP-9 production in diabetic wounds. Multiplex immunoassay revealed that the TRF modulated proinflammatory cytokine and chemokine production. However, it increased interleukin-4 (IL-4) and vascular endothelial growth factor (VEGF) production and reduced granulocyte-macrophage colony-stimulating factor (GM-CSF). Our data suggest that topical TRF application may enhance diabetic cutaneous wound healing.
\end{abstract}

Keywords: diabetic mice, diabetes mellitus, skin, tocotrienol-rich fraction, wound healing.

Received: 26 April 2021; Accepted: 15 November 2021; Published online: 5 January 2022.

Malaysian Palm Oil Board,

6 Persiaran Institusi, Bandar Baru Bangi,

43000 Kajang, Selangor, Malaysia.

2 Department of Biochemistry, Faculty of Medicine, Universiti Kebangsaan Malaysia, UKM Medical Center, Jalan Yaacob Latif, Bandar Tun Razak Cheras, 56000 Kuala Lumpur, Malaysia.

3 Department of Pathology, Faculty of Medicine, Universiti Kebangsaan Malaysia, UKM Medical Center, Jalan Yaacob Latif, Bandar Tun Razak, 56000 Kuala Lumpur, Malaysia.

* Corresponding author e-mail: zaizuhana@mpob.gov.my

\section{INTRODUCTION}

The most common type of diabetes is type 2 diabetes (T2D) mellitus (Tsalamandris et al., 2019). T2D patients have a greater risk of limb amputation than nondiabetic individuals due to impaired wound healing (Zheng et al., 2018). Wound healing is multifactorial, and it requires homeostasis, inflammation, proliferation, and tissue remodelling (Rodrigues et al., 2019; Thangavel et al., 2018; Xiao et al., 2020). However, wound healing is delayed in diabetic patients for many reasons, including persistent inflammatory and high oxidative stress states, resulting in abnormal angiogenesis and 
neuropathy (Katsuhiro et al., 2018; Strang et al., 2020; Yuan et al., 2018).

Although inflammation is an essential part of healing, disproportionate inflammation leads to disruptions in the normal healing cascade (Strang et al., 2020; Zhao et al., 2016), such as in the skin of diabetic mice (Brandt et al., 2018). Inflammation and the immune system are modulated by cytokines and extracellular signalling proteins (Fields et al., 2019). Dysregulated production of these proteins results in impaired diabetic wound healing (Strang et al., 2020). Thus, regulating inflammation through its mediators and increasing antioxidant activities may improve cutaneous wound healing in diabetic patients (Zhao et al., 2016).

A study performed on diabetic patients showed reductions in catalase (CAT) and glutathione peroxidase (GPx) activities and an overall decrease in antioxidant levels (Alghazeer et al., 2018). The reduction in antioxidant defence, which is one of the detrimental effects of reactive oxygen species (ROS) on cellular homeostasis, often worsens redox imbalance (Cano Sanchez et al., 2018). Diabetic complications mainly occur when ROS production induced by diabetes stimulates various pathological signalling pathways that lead to tissue injury (Deng et al., 2021; Zhao et al., 2016). Therefore, increasing antioxidant activity may enhance wound healing (Zhao et al., 2016).

During inflammation or oxidative stress, neutrophils secrete a certain amount of myeloperoxidase (MPO) to help recover from tissue injury (Khan et al., 2018). While excessive MPOactivity is detrimental to tissue recovery, MPO is an important indicator of inflammation and the oxidative stress response (Khan et al., 2018). The structural protein, collagen is essential for tissue regeneration and dermal reconstruction (Thangavel et al., 2017), and collagen deposition in the wound can be indicated by hydroxyproline content (Hemmati et al., 2018).

It was previously reported that low transforming growth factor beta (TGF- $\beta$ ) levels can predict the chronicity of diabetic wounds (Liarte et al., 2020). Transforming growth factor beta-1 (TGF- $\beta 1$ ) is known to stimulate collagen production in dermal fibroblasts to achieve wound contraction (Serra et al., 2017) and closure. In contrast, metalloproteinase-9 (MMP-9) leads to excessive degradation of the extracellular matrix and reduces the tensile stress of the wound. MMP-9 is highly expressed in diabetic wounds (Ayuk et al., 2016) and is considered the primary cause of diabetic foot ulcer recalcitrance in healing (Jones et al., 2019). Thus, this proteinase would be an excellent candidate in a study regarding the treatment of diabetic wounds.

The tocotrienol-rich fraction (TRF) is a blend of tocotrienol $(\sim 70 \%)$ and alpha-tocopherol $(\sim 30 \%)$. It has been reported that the tocotrienol/tocopherol ratios in rice bran oil, barley, and palm oil are 1:1, 1.9:1, and 3:1, respectively (Cheng et al., 2017). As a rich source of vitamin $\mathrm{E}$, the TRF has an abundance of antioxidative (Khor et al., 2017; Matough et al., 2014; Shahidi and De Camargo, 2016) and anti-inflammatory (Nor Azman et al., 2018; Yap, 2018) properties. No adverse skin reactions after the topical application of tocotrienols have been reported (Hasan et al., 2018). Wound recovery in diabetic (streptozotocin-induced) and normal rats could be enhanced by the TRF (Elsy et al., 2017; Musalmah et al., 2005), and topical treatment with the TRF could also promote burn healing (Elsy et al., 2017). Despite years of research, the pathogenesis of impaired cutaneous wounds in T2D patients remains incompletely understood, and there is still a need to identify therapeutic approaches and remedies for wounds. Furthermore, alternative therapeutic treatments using natural products are in high demand. In view of the background of the TRF and to the best of our knowledge, studies using the TRF in T2D skin wound healing are very limited. Therefore, the current study aimed to evaluate cutaneous wound healing in a T2D model that was topically treated with the TRF.

\section{MATERIALS AND METHODS}

\section{Reagents}

In this study, palm-based TRF Gold Tri E 70 was purchased from Sime Darby Food and Beverages Marketing Sdn. Bhd. (Selangor, Malaysia). The TRF $(10 \%, \mathrm{w} / \mathrm{w})$ was loaded in vehicle consisting of PEG-400 (85\%, w/w, Sigma-Aldrich, USA, Cat No. 202398) with Tween ${ }^{\circledR} 80(5 \% \mathrm{w} / \mathrm{w}$, Polysorbate, Sigma-Aldrich, USA, Cat No. 59924).

\section{Diabetic and Normal Mouse Models}

Type 2 diabetic (T2D) and obese (B6. V-Lepob/ obJRj) male mice were obtained from Janvier Laboratory (France), and lean male mice (C57BL / 6) were used as the normal control. The levels of fasting blood glucose and serum insulin were determined using an Accu-Chek device (Roche, $\mathrm{GmbH}$, Mannheim, Germany) and ELISA (Rat/ Mouse Insulin Kit; Millipore, St. Charles, MO, USA) to validate the development of diabetes in the mouse models. Mice with blood glucose exceeding $300 \mathrm{mg} \mathrm{dl}^{-1}$ were considered hyperglycaemic. The body weights of the mice were recorded at every postinjury time point. All procedures were strictly performed based on the approved protocols by the Universiti Kebangsaan Malaysia Animal Care and Use Committee (UKMAEC, procedure number: BIOK/ PP2017 / SUZANA / 25-JAN. / 817-JAN.-2017SEPT.-2018). The mice were subjected to a cutaneous 
wounding experiment and randomly divided into three groups of 12 mice.

Group I: Normal control (wild-type, received vehicle only)

Group II: T2D control (received vehicle only)

Group III: T2D treated (received TRF in vehicle)

\section{Cutaneous Wound Model with Full-thickness Skin Excision}

Four full-thickness skin excision wounds were made on the dorsum of the mice using a sterile $5 \mathrm{~mm}$ punch biopsy (Kai Medical, Japan) under anaesthesia (sodium pentobarbital, $60 \mathrm{mg} \mathrm{kg}^{-1}$ ). Subsequently, a silicone wound splint (Grace Bio-Labs Oregon, USA) was used to secure the wound perimeter and prevent contraction. Topical application of the TRF was performed twice daily, and the wounds were covered with a transparent dressing (Tegaderm, 3M Health Care, St. Paul, MN, USA Cat. No. 1624) after the treatment. All mice were kept in a controlled environment at a temperature of $21 \pm 0.5^{\circ} \mathrm{C}$, relative humidity of $50 \pm 10 \%$, and a 12-hr alternating light and dark schedule. Water and food were provided ad libitum.

\section{Measurement of Wound Closure Kinetics}

Images of the wounds were captured on days 0 , $1,3,7$ and 14 using a digital camera beginning on the first day of skin excision until day 14. Images were examined using image processing software (ImageJ, version 1.5e, NIH, USA). The percentage of wound closure was calculated as follows:

$$
\begin{gathered}
\% \text { wound } \\
\text { closure }
\end{gathered}=\frac{\begin{array}{c}
\text { initial wound area (day } 0)- \\
\text { wound area at } n
\end{array}}{\text { wound area day } 0} \times 100
$$

where, $\mathrm{n}=$ number of days $(0,1,3,7$ and 14 days) after skin excision.

Histopathological and Immunohistochemical Examination of Wound Tissues

Excised wound tissues were prepared for clinical pathology on the indicated days postinjury. The tissues were fixed with buffered formalin $(10 \%)$ obtained from Sigma-Aldrich (USA) and dehydrated before being converted into paraffin-embedded blocks. Tissue sections with a thickness of $4 \mu \mathrm{m}$ were prepared and stained with haematoxylin and eosin (H\&E) (Leica, Germany) to assess cellular responses to the treatments and stained with Masson's trichrome on day 14 to observe collagen deposition in the wound tissue according to the manufacturer's protocol. A semiquantitative method was used to examine the following processes: inflammatory cell infiltration, epidermal regeneration (re-epithelialisation), fibroblast proliferation and collagen deposition. Three stained sections in each group were evaluated and scored using a scale, as summarised in Table 1. To detect the presence of CD31, immunohistochemistry was conducted. Briefly, the sections were blocked with $3 \%$ BSA at $37^{\circ} \mathrm{C}$ for $30 \mathrm{~min}$, followed by incubation with CD31 antibodies (1:100, goat, Servicebio, GB13063) at $4^{\circ} \mathrm{C}$ overnight. After being washed with phosphate buffered saline (PBS), a goat anti-rabbit secondary antibody (Servicebio, GB23204, 1:200) coupled with horseradish peroxidase was added. The samples were incubated at $37^{\circ} \mathrm{C}$ for $1 \mathrm{hr}$. The sections were stained with diaminobenzidine tetrahydrochloride (Servicebio, G1211) and lightly counterstained with haematoxylin. Positive immunohistochemical staining was observed as brown staining. The number of blood vessels in three tissue sections was assessed using the microvessel density (MVD) counting technique, whereby the average number of microvessels per high-power field (HPF) was estimated by counting CD31-stained cells. All sections were examined using a digital microscope (Eclipse 200, Nikon Instruments, Inc., Melville, NY) and evaluated by pathologists in a single-blind manner.

\section{Determination of CAT, GPx and MPO Activities in Wound Tissues}

CAT and GPx activities were assessed using kits from Cayman Chemical (Ann Arbor, MI, USA), whereas MPO was assessed using kits from (BioVision Inc., USA) according to the manufacturer's protocol.

\section{Protein and Hydroxyproline Measurement}

Protein and hydroxyproline levels in wound tissues were measured using commercial assay kits

\begin{tabular}{|c|c|c|c|c|c|}
\hline Histological score & 0 & 1 & 2 & 3 & 4 \\
\hline Presence of inflammatory cells & Absent & Occasionally present & Light scattering & Abundant & Confluent \\
\hline Fibroblast proliferation & Absent & Occasionally present & Light scattering & Abundant & - \\
\hline Epidermal regeneration & None & Mild & Moderate & Complete & - \\
\hline Collagen & None & Present & Mild & Moderate & Intense \\
\hline
\end{tabular}

TABLE 1. HISTOLOGICAL FEATURES AND SCORING 
from Cayman Chemical (Ann Arbor, MI, USA) and BioVision Inc. (USA), respectively, according to the manufacturer's instructions.

\section{Measurement of MMP-9 and TGF- $\beta 1$ Levels in Granulation Tissues}

MMP-9 and TGF- $\beta 1$ levels in wound tissues were examined using a Fine Test ELISA kit for mice from Wuhan Fine Biotech Co., Ltd. (Wuhan, China) per the manufacturer's protocols.

\section{Multiplex Cytokine Analysis}

A custom-made multiplex analysis was performed based on xMAP Luminex technology using a ProcartaPlex ${ }^{\mathrm{TM}}$ cytokine 36 plex assay from Thermo Fisher Scientific Inc. according to the manufacturer's protocol. Measurements were performed using Luminex 200 with xPONENT $^{\circledR}$ software version 3.1, and the concentration of cytokines was determined using MasterPlex QT software version 2.0.0.59.

\section{Statistical Analysis}

All experiments were conducted in replicates. The data were subjected to statistical analysis using the Statistical Package for Social Sciences (SPSS) version 22. A $p$ value less than 0.05 was considered significant.

\section{RESULTS AND DISCUSSION}

All diabetic mice had significantly higher $(p<0.01)$ body weights throughout the study duration than those in the normal control group (Figure 1a). For example, the mean measurement for the T2D control group was $41.33 \pm 0.84 \mathrm{~g}$ on day 1 and $43.06 \pm 0.26$ $\mathrm{g}$ on day 14 and that for the TRF-treated group was $41.75 \pm 0.10$ on day 1 and $42.98 \pm 0.60 \mathrm{~g}$ on day 14 . Moreover, normal control mice exhibited body weights of $26.24 \pm 0.60 \mathrm{~g}$ on day 1 and $27.33 \pm 0.45$ $\mathrm{g}$ on day 14 (Figure 1a). Blood glucose levels were significantly $(p<0.01)$ higher in the T2D control group $\left(362.67 \pm 5.24 \mathrm{mg} \mathrm{dl}^{-1}\right.$ (day 1$)$ and $372.00 \pm 4.16$ $\mathrm{mg} \mathrm{dl}^{-1}$ (day 14) and the TRF-treated group (355.00 $\pm 9.54 \mathrm{mg} \mathrm{dl}^{-1}$ (day 1) and $377.33 \pm 5.80 \mathrm{mg} \mathrm{dl}^{-1}$ (day 14) than in the normal control group (120.00 \pm 12.70 $\mathrm{mg} \mathrm{dl}^{-1}$, day 1 and $151.70 \pm 13.70 \mathrm{mg} \mathrm{dl}^{-1}$, day 14) (Figure 1b). The normal control group also exhibited significantly $(p<0.01)$ lower serum insulin levels on day $1\left(1.67 \pm 0.03 \mathrm{ng} \mathrm{ml}^{-1}\right)$ and day $14(1.54 \pm 0.13$

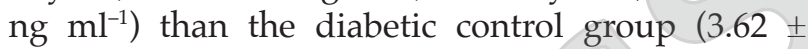
$\left.0.22 \mathrm{ng} \mathrm{ml}^{-1}\right)$ on days 1 and $14\left(3.70 \pm 0.03 \mathrm{ng} \mathrm{ml}^{-1}\right)$. TRF-treated mice also showed significantly lower $(p<0.01)$ insulin levels on day $1\left(3.66 \pm 0.04 \mathrm{ng} \mathrm{ml}^{-1}\right)$ and day $14\left(3.75 \pm 0.02 \mathrm{ng} \mathrm{ml}^{-1}\right)$ than those in the normal control group (Figure 1c).

\section{Wound Closure and Histological Effects of the TRF on Cutaneous Wound Healing}

Wound kinetics and macroscopic assessments. Wound kinetic and macroscopic assessments of all mice were measured on days 0, 1, 3, 7 and 14, and the excised wound site was photographed as shown in Figure 2. Normal control mice showed the fastest wound closure rate, and the wounds were completely closed $(100 \%)$ on day 14 with visible hair growth. In contrast, T2D controls showed significantly slower $(p<0.01)$ rates at days 3, 7 and 14 than the normal controls. However, TRF-treated wounds showed significantly higher $(p<0.05)$ wound closure rates on days 3, 7 and 14 than T2D control wounds (Figure $2 b)$.

Histological assessments. Previous findings were consistent with the histological examination (Figure $3 a$ ). Wound sections in all groups showed the presence of inflammatory cells on day 3 . These immune cells are the key regulators and players during acute wound healing and prevent infection (Peiseler and Kubes, 2019). Immune cell infiltration is followed by alterations from a proinflammatory to (a)

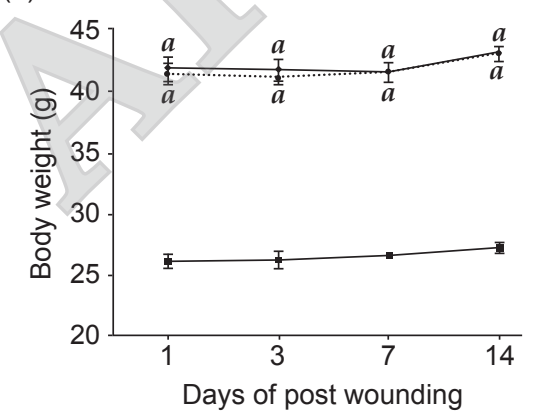

(b)

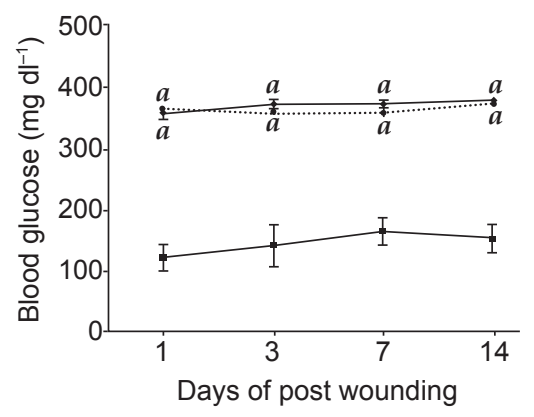

(c)

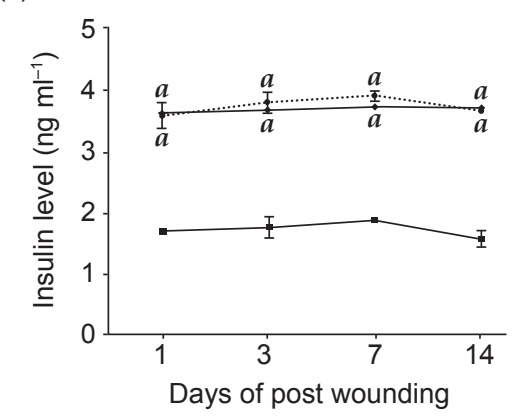

Figure 1. (a) Body weights, (b) blood glucose levels, and (c) insulin levels of the mice. The data are expressed as the mean \pm SEM ( $n=3$ ) and were analysed using two-way ANOVA with Tukey's multiple comparison test. ${ }^{a} \mathrm{p}<0.01$ compared with the normal control group. 
(a)

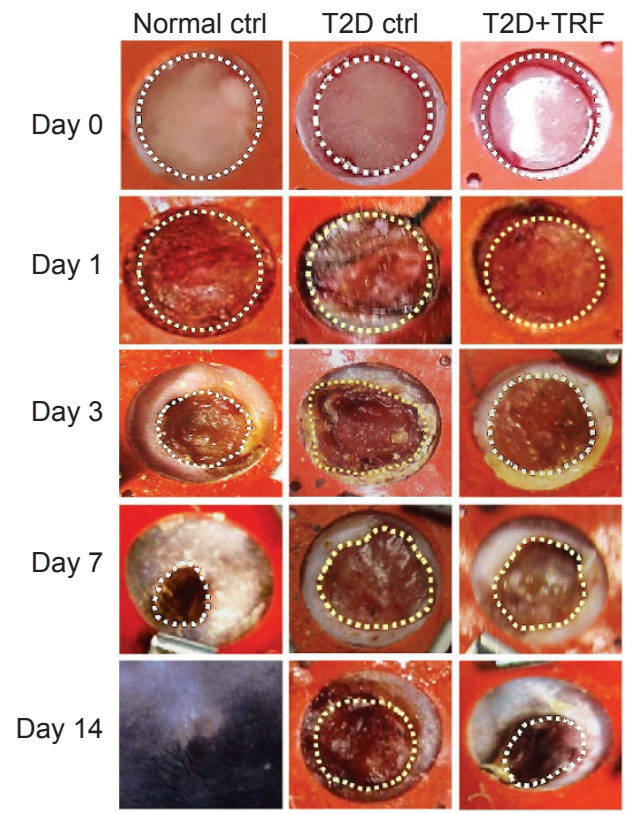

(b)

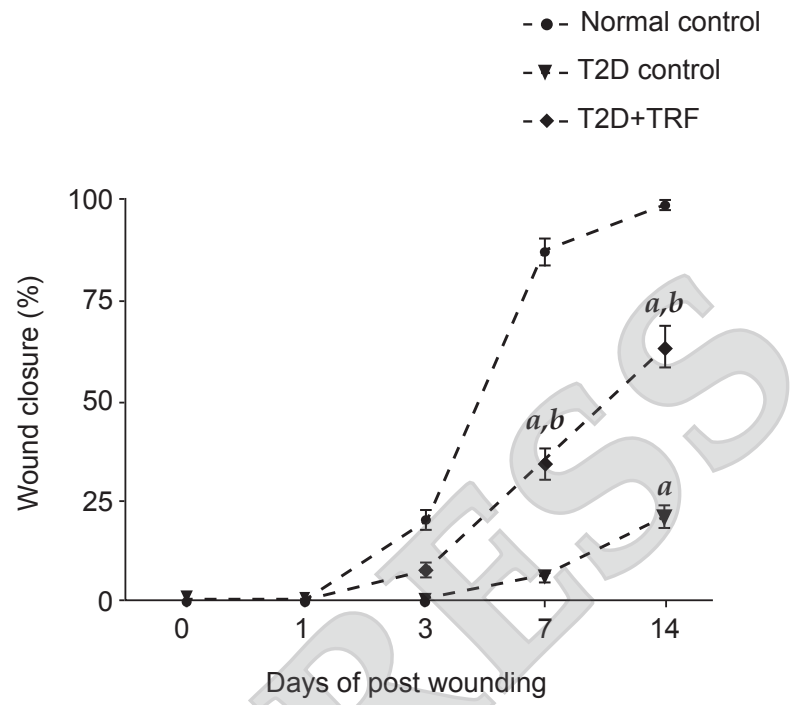

Figure 2. Effects of the TRF on wound closure. (a) Representative images of the gross appearance of wounds, and (b) the percentage of wound closure. The wound closure data are the mean \pm SEM ( $n=3,12$ wounds/group) and were calculated by two-way ANOVA with Tukey's multiple comparison test. ${ }^{a} \mathrm{p}<0.01$ vs. the normal control, ${ }^{b} \mathrm{p}<0.05$ vs. the T2D control.

a healing immune response to inhibit inflammation and initiate the tissue remodelling process (Raziyeva et al., 2021).

In the present study, the normal control wound exhibited standard healing stages, whereby thin re-epithelialisation was observed as early as day 3 after wounding and continued until day 7 . The wound surface was also fully covered on day 14 . In addition, the presence of more fibroblasts and blood vessels was also evident in the normal control group than in the other groups. In contrast, the T2D controls showed an abundance of inflammatory cells and disorganised structures, but TRF-treated wounds showed a moderate inflammatory response compared to diabetic controls.

On day 7, the T2D control group showed marked dominance of inflammatory cells with few fibroblasts, but in TRF-treated wounds, the inflammatory cells seemed to subside, and the wounds showed wellformed granulation tissue, which was covered by more blood vessels and fibroblasts with some collagen deposition than those in the T2D control. On day 14, the wound sections in the diabetic control group showed the presence of blood vessels and were dominated by inflammatory cells compared to TRF-treated wounds, whereby thicker granulation tissue was dominated by fibroblasts with adequate, more organised, and compact collagen deposition and a completely newly regenerated epithelial layer.

In addition, histological scoring of inflammation, fibroblast proliferation, re-epithelialisation and collagen deposition was performed (Figure 3b). The results showed that the proportion of inflammatory cells was significantly reduced at days $3(p<0.01)$, $7(p<0.05)$ and $14(p<0.05)$ in TRF-treated wounds compared to T2D control wounds. Moreover, the rate of fibroblast proliferation was significantly increased in TRF-treated diabetic wounds on days $3(p<0.05), 7 \quad(p<0.01)$ and $14(p<0.001)$ compared with diabetic wounds. The T2D control group demonstrated incomplete re-epithelialisation and poorly formed granulation tissue, but TRF-treated wounds showed significantly higher epidermal regeneration on days $3(p<0.05), 7(p<0.001)$ and $14(p<0.01)$ with denser collagen deposition on days $7(p<0.01)$ and $14(p<0.001)$ than the diabetic control (Figure $3 b$ ). We showed that T2D wounds sustained production of inflammatory cells in the wound sites, which blocked the progression of healing, thus, impeding wound closure (Tan et al., 2019). Dysfunctional fibroblasts and epidermal cells, failed angiogenesis and impaired tissue maturation (Daemi et al., 2019; Manzouerh et al., 2019; Thangavel et al., 2017) were observed in this group.

Diabetic wound healing is impaired due to improper angiogenesis (Okonkwo and DiPietro, 2017). To understand the effect of the TRF on angiogenesis, the wound sections were stained with CD31 (Figure 3c) and quantified (Figure 3d). The diabetic controls showed a few immature blood vessels compared to normal controls and TRFtreated wounds on days 7 and 14. A few densely packed vessels were also observed. In comparison to the T2D control, TRF treatment significantly $(p<0.001)$ increased the number of CD31-positive cells on days 7 and 14 .

Collagen is the major component of the extracellular matrix, which is essential for wound closure. Collagen synthesis, deposition, remodelling 
and maturation are crucial during tissue repair and regeneration (Thangavel et al., 2017). Collagen biosynthesis in tissue sections was examined by Masson's trichrome staining (Daemi et al., 2019; Zadeh Gharaboghaz et al., 2020) on day 14 (Figure 3e). The results showed that granulation tissues in TRFtreated diabetic wounds exhibited collagen densities that were similar to those of normal wound healing. Treatment with the TRF induced significantly higher collagen synthesis and deposition than diabetic control wounds. This result suggests that topical application of the TRF may improve collagen synthesis, maturation and deposition.

\section{Protein and Hydroxyproline Levels in Wound Tissues}

Protein and hydroxyproline levels were measured on days 7 and 14 (Table 2). The level of protein indicates the cellular proliferation rate in the wound site (Lin et al., 2012). The protein level in the T2D control group was significantly lower $(p<0.05)$ than that in the normal control on days 7 and 14. However, TRF treatment significantly increased $(p<0.01)$ the protein level on days 7 and $14(p<0.05)$ compared to that in the T2D control. The hydroxyproline level was also significantly reduced $(p<0.001)$ on days 7 and 14 in the T2D group compared to the normal control. However, TRF-treated wounds showed a significant $(p<0.001)$ increase in hydroxyproline on days 7 and 14 . The concentration of hydroxyproline reflects the collagen concentration in tissue, and a higher concentration indicates a faster rate of wound healing, providing the tissue matrix with integrity and strength (Dwivedi et al., 2017). A high hydroxyproline level also indicates an increase in cellular proliferation and collagen synthesis (Dwivedi et al., 2017).

(a)

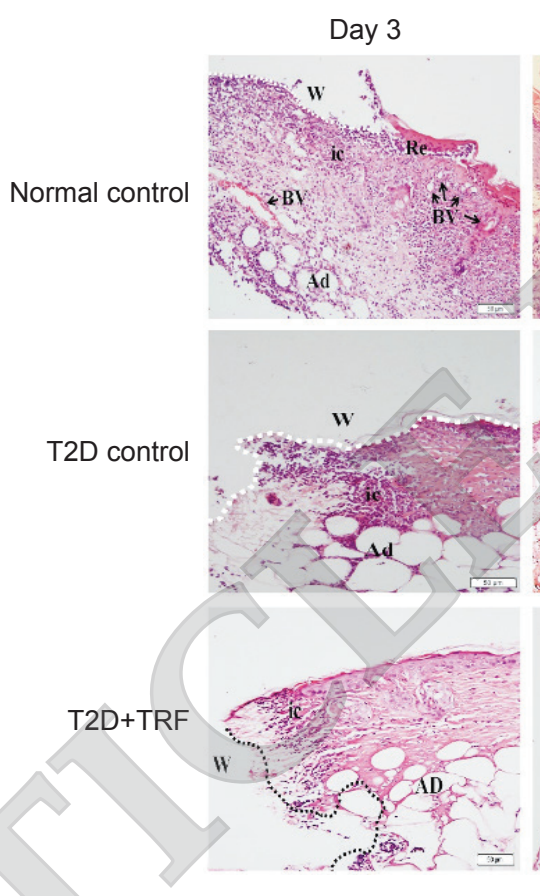

Day 3

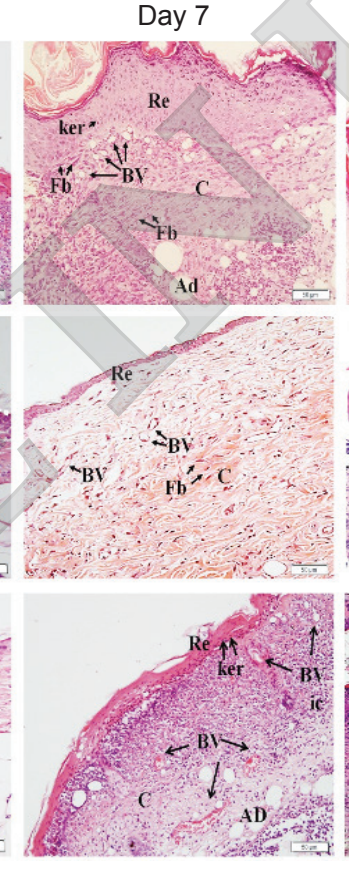

Day 14

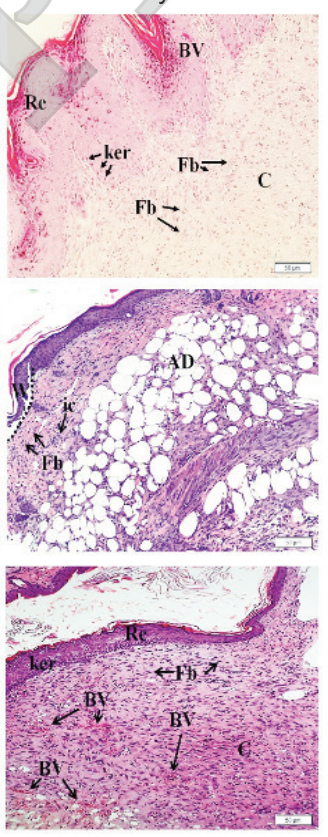

(b)
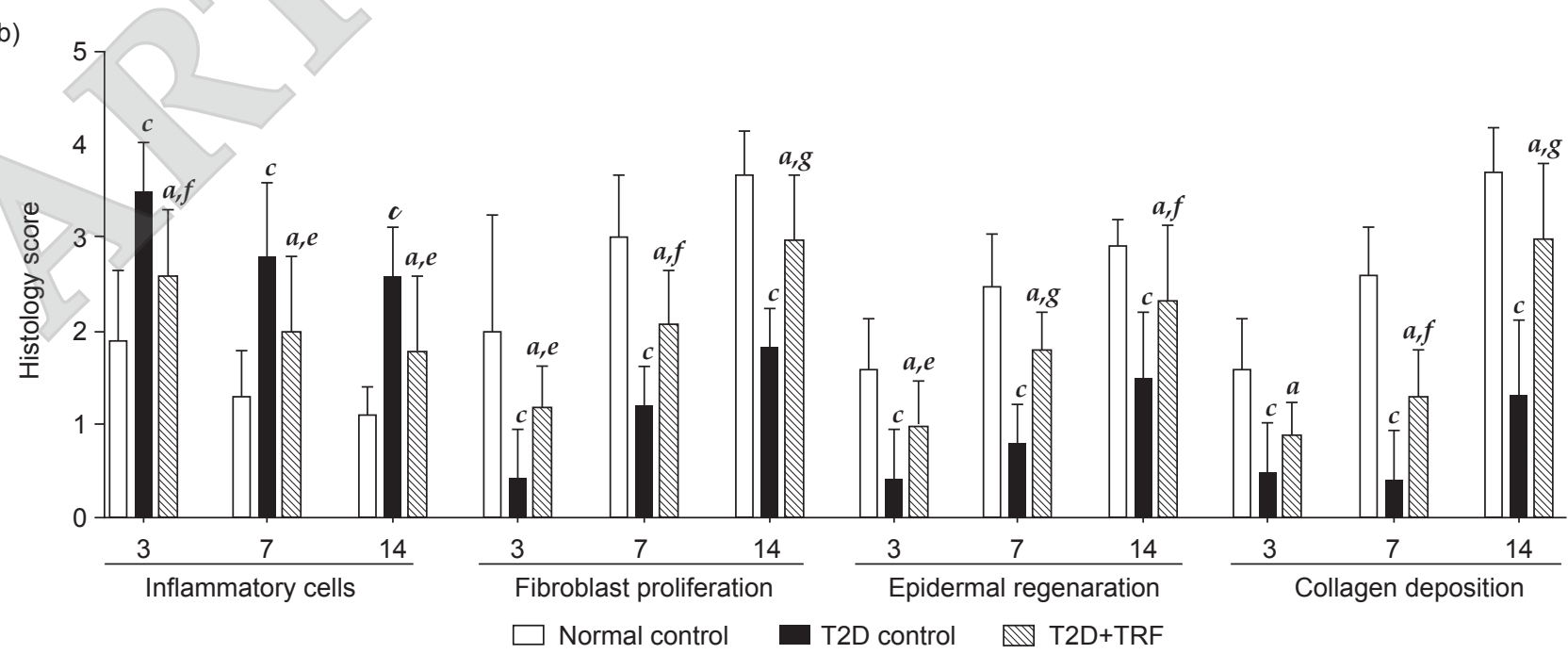
(c)

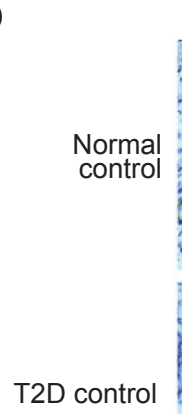

T2D+TRF
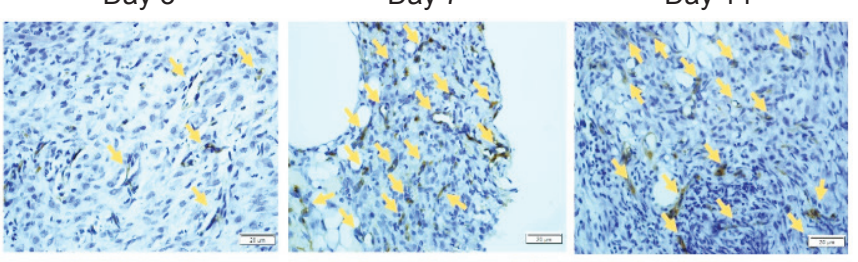

(d)

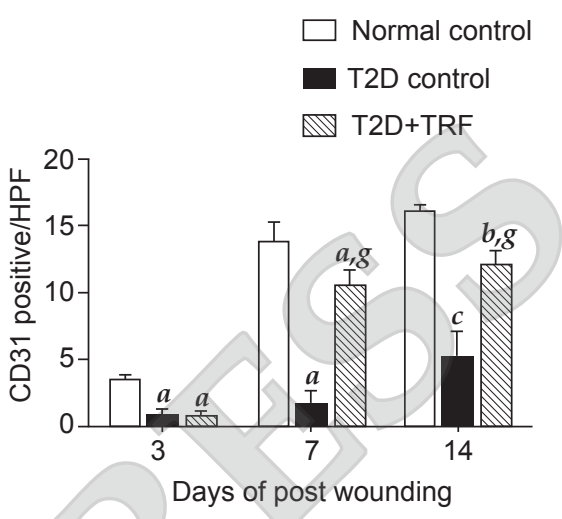

(e)

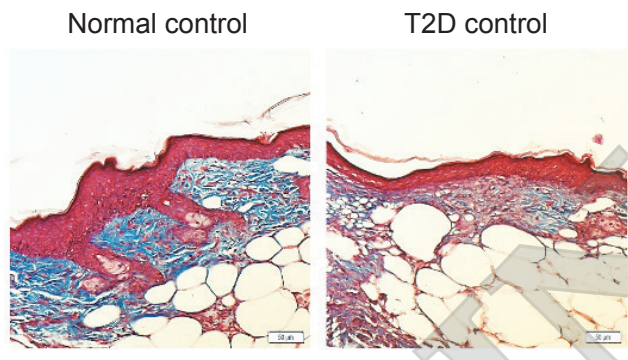

T2D control

T2D+TRF

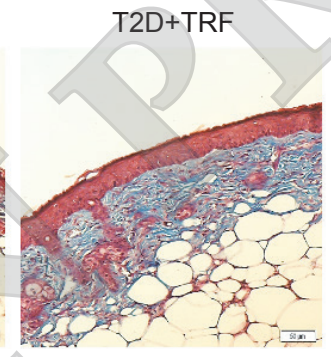

Figure 3. Representative photomicrographs showing the histological features of wounds using (a) HEE staining (n=3). Magnification (20x) with a scale bar of $50 \mu \mathrm{m} ; \mathrm{W}$, wound (dotted line); BV, blood vessel; AD adipose tissue; SC, subcutaneous; Fb, fibroblast; ic, inflammatory cell. (b) Histological score of inflammatory cell infiltration, fibroblast proliferation, epidermal regeneration and collagen deposition ( $n=3)$. (c) CD31-stained granulation tissues on days 3, 7 and 14. (d) Number of CD31-positive cells on days 3, 7 and 14 ( $n=3$ ). Yellow arrows show the formation of blood vessels. (e) Masson's trichrome staining ( $n=3)$ on day 14 . Blue staining represents collagen fibre deposition in the wounds. The data are the mean \pm $\operatorname{SEM}(n=3)$ and were calculated using two-way ANOVA with Tukey's multiple comparison test. ${ }^{a} \mathrm{p}<0.05,{ }^{b} \mathrm{p}<0.01,{ }^{c} \mathrm{p}<0.001$ vs. the normal control; ${ }^{e} \mathrm{p}<0.05,{ }^{f} \mathrm{p}<0.01,{ }^{8} \mathrm{p}<0.001$ vs. the T2D control.

\section{Effect of the TRF on TGF- $\beta 1$ and MMP-9 Levels}

TGF- $\beta$, a transforming growth factor, plays a critical role in each phase of wound healing by suppressing the inflammatory response and supporting granulation tissue development at the wound site (Wang et al., 2017). A significant reduction $(p<0.001)$ in TGF- $\beta 1$ levels was observed in T2D control wound tissue compared to normal control wound tissue on days 7 and 14 . However, TRF treatment significantly $(p<0.001)$ increased the level of TGF- $\beta 1$ on days 7 and 14 compared to that in the diabetic control.

High levels of MMP-9 in diabetic wounds often lead to excessive degradation of the extracellular matrix and reduced tensile strength of the wound (Ayuk et al., 2016). Our data showed significantly higher $(p<0.001)$ concentrations of MMP-9 in T2D control wounds than in normal control wounds on days 7 and 14. However, treatment with the TRF significantly decreased MMP-9 production on days 7 and $14(p<0.001)$ compared to those in the diabetic control (Table 2).

\section{The TRF Reduces Oxidative Stress in Diabetic Wounds}

The first line of defence against oxidants during injury involves the antioxidants CAT and GPx (Ighodaro and Akinloye, 2018; Kurahasi and Fujii, 2015). In the present study, the T2D control group showed significantly lower $(p<0.05)$ CAT activity on days 7 and 14 than the normal control group. However, TRF treatment significantly increased CAT activity on days $7(p<0.01)$ and $14(p<0.05)$ compared to that in the T2D control (Figure 4a). The T2D control group showed significantly $(p<0.05)$ lower GPx activity on days 7 and 14 postinjury than the normal controls. In contrast, TRF-treated wounds showed significantly $(p<0.05)$ higher GPx activity on day 14 than T2D control wounds (Figure $4 b$ ). The TRF has also been reported to increase other antioxidants, such as superoxide dismutase (SOD) and glutathione (GSH), but reduce lipid peroxidation in T2D wounds (Shahrim et al., 2016; 2019).

Myeloperoxidase protects against infection during injury by killing pathogens. It also acts as 
TABLE 2. EFFECT OF THE TRF ON PROTEIN, HYDROXYPROLINE, TGF-B1 AND MMP-9 LEVELS

\begin{tabular}{|c|c|c|c|c|c|c|c|c|}
\hline \multirow[t]{2}{*}{ Group } & \multicolumn{2}{|c|}{$\begin{array}{c}\text { Protein content } \\
\left(\mu \mathrm{g} 100 \mathrm{mg}^{-1} \text { tissue }\right)\end{array}$} & \multicolumn{2}{|c|}{$\begin{array}{c}\text { Hydroxyproline } \\
\text { ( } \mu \mathrm{g} 100 \mathrm{mg}^{-1} \text { tissue) }\end{array}$} & \multicolumn{2}{|c|}{$\begin{array}{c}\text { TGF- } \beta 1 \\
\left(\mathrm{pg} \mathrm{ml}^{-1}\right)\end{array}$} & \multicolumn{2}{|c|}{$\begin{array}{l}\text { MMP-9 } \\
\left(\mathrm{pg} \mathrm{ml}^{-1}\right)\end{array}$} \\
\hline & Day 7 & Day 14 & Day 7 & Day 14 & Day 7 & Day 14 & Day 7 & Day 14 \\
\hline Normal ctrl & $69.23 \pm 4.96$ & $54.06 \pm 5.96$ & $234.03 \pm 4.59$ & $127.34 \pm 0.653$ & $183.54 \pm 3.33$ & $226.83 \pm 20.09$ & $25.88 \pm 0.81$ & $17.24 \pm 1.50$ \\
\hline T2D ctrl & $48.78 \pm 6.55^{a}$ & $51.37 \pm 5.91^{a}$ & $47.42 \pm 0.38^{c}$ & $54.60 \pm 0.38^{c}$ & $43.01 \pm 1.51^{c}$ & $65.21 \pm 1.97^{c}$ & $70.33 \pm 0.16^{c}$ & $57.61 \pm 0.44^{c}$ \\
\hline $\mathrm{T} 2 \mathrm{D}+\mathrm{TRF}$ & $63.76 \pm 5.16^{e}$ & $70.83 \pm 3.95^{a, d}$ & $185.40 \pm 4.94^{c, f}$ & $134.51 \pm 5.32^{c, f}$ & $145.46 \pm 1.70^{c, f}$ & $123.06 \pm 1.11^{c, f}$ & $29.21 \pm 3.49^{f}$ & $20.68 \pm 0.30^{f}$ \\
\hline
\end{tabular}

Note: The values are expressed as the mean $\pm \operatorname{SEM}(\mathrm{n}=3)$ of the level of protein, hydroxyproline, TGF- $\beta 1$, and MMP-9 and were analysed using two-way ANOVA with Tukey's multiple comparison test. ${ }^{a} p<0.05,{ }^{b} p<0.01,{ }^{c} p<0.001$ vs. the normal control. ${ }^{\mathrm{d}} p<0.05,{ }^{\mathrm{e}} p<0.01$, ${ }^{\mathrm{f}} p<0.001$ vs. the T2D control.

an indicator of neutrophil infiltration in the wound site, which is the first sign of inflammation or injury to cells and tissues (Khan et al., 2018). However, MPO could induce oxidative stress, inflammation, and tissue damage when its levels become too high (Ferdous et al., 2020). MPO activity was significantly higher $(p<0.05)$ on day 7 in the T2D control group than in the normal control group. However, the TRF significantly $(p<0.05)$ attenuated MPO activity on day 7 compared to that in the T2D control (Figure 4c).

\section{Cytokine Profile of T2D Wounds Treated with the TRF}

A multiplex protein array was carried out to determine the effects of TRF on cytokine levels in tissue collected from wounds on days 1, 3, 7 and 14. This analysis included the proinflammatory interleukin family (IL- $1 \alpha$ and IL-17A), leukaemia inhibitory factor (LIF) and interleukin-4 (IL-4), which are anti-inflammatory markers. The chemokines analysed included eotaxin, monocyte chemoattractant protein-1 (MCP-1), MCP-3, macrophage inflammatory proteins-1 alpha (MIP$1 \alpha)$, regulated upon activation, normal $\mathrm{T}$ cell expressed and presumably secreted (RANTES),
LIX/CXCL-5 (C-X-C motif chemokine 5), growth regulated oncogene (GRO- $\alpha$ ), macrophage inflammatory protein-2 (MIP-2) and interferon gamma-induced protein 10 (IP-10). Growth factors such as granulocyte-macrophage colony-stimulating factor (GM-CSF) and vascular endothelial growth factor (VEGF) were also examined.

Inflammatory mediators are mostly synthesised de novo by activated cells in response to wounding (Chang et al., 2018). Chronic wounds are in a persistent inflammatory state, as indicated by excessive inflammatory mediator release (Ligi et al., 2016). Profound increases in proinflammatory cytokines (IL-1 $\alpha$, IL-17A, and LIF) were observed in T2D wounds compared to normal controls (Figures $5 a-c)$. Our results showed that treatment with the TRF significantly abated proinflammatory cytokine production, particularly that of IL- $1 \alpha$, on day 1 $(p<0.001)$, day $3(p<0.05)$, day $7(p<0.05)$, and day $14(p<0.01)$ (Figure 5a). IL-17A was also reported to be involved in the pathogenesis of chronic wounds (Hadian et al., 2019). This study showed that TRF treatment significantly mitigated IL-17A at day 7 $(p<0.05)$ compared to that in the diabetic control (Figure $5 b$ ). Moreover, LIF, a cytokine belonging to the IL-6 family, was significantly increased in the T2D group; however, the TRF-treated group exhibited a (a)

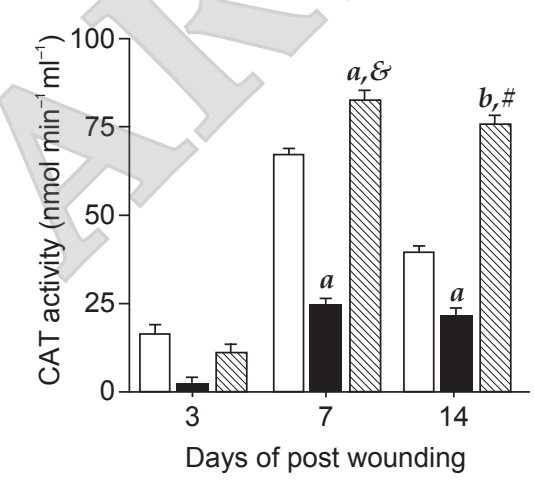

(b)

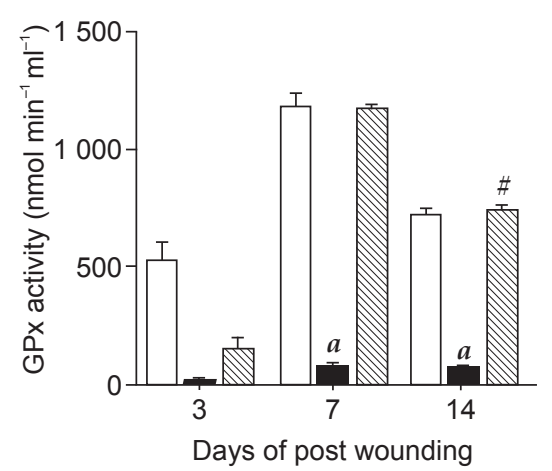

(c)

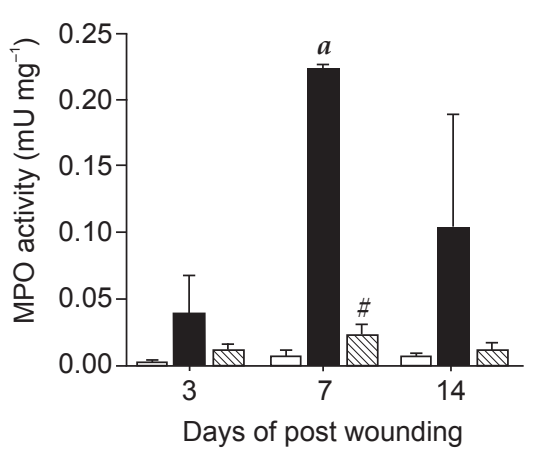

Days of post wounding

Normal control

T2D control

T2D+TRF

Figure 4. Effects of the TRF on (a) CAT, (b) GPx, and (c) MPO activities in wound tissues. The data are the mean $\pm S E M(n=3)$ and were calculated using two-way ANOVA with Tukey's multiple comparison test. ${ }^{a} \mathrm{p}<0.05,{ }^{b} \mathrm{p}<0.01$ vs. the normal control; ${ }^{\sharp} \mathrm{p}<0.05,{ }^{8} \mathrm{p}<0.001$ vs. the T2D control. 
reduction in LIF on day $1(p<0.05)$, day $3(p<0.001)$, and day $7(p<0.001)$ compared to the diabetic control (Figure 5c).

IL-4 production was significantly increased in TRF-treated wound on day $1(p<0.01)$, day $3(p<0.05)$, and day $7(p<0.05)$ compared to that in T2D control wounds (Figure $5 d$ ). This anti-inflammatory marker significantly contributes to the healing process in wounds by promoting neuronal and glial survival by inhibiting the local response to inflammation, as well as signalling nerve growth factor production and GM-CSF, which are beneficial for diabetic peripheral neuropathy (Zhao et al., 2016).

Our findings also showed a significant increase $(p<0.05)$ in eotaxin in TRF-treated wounds on days 3, 7 and 14 compared to T2D control wounds (Figure $6 a$ ). This increase might be related to the function of eotaxin, a chemotactic protein that attracts eosinophils and promotes collagen deposition, angiogenesis, and mitogenesis during injury (Burns et al., 2020). Eotaxin is a proinflammatory chemokine, is a small chemotactic cytokine that is secreted by a variety of cells in the wound (Ridiandries et al., 2018) and functions to regulate the migration of cells to the injured area (Sokol and Luster, 2015). The chemokines MCP-1 and MIP-2 are known to

(a)

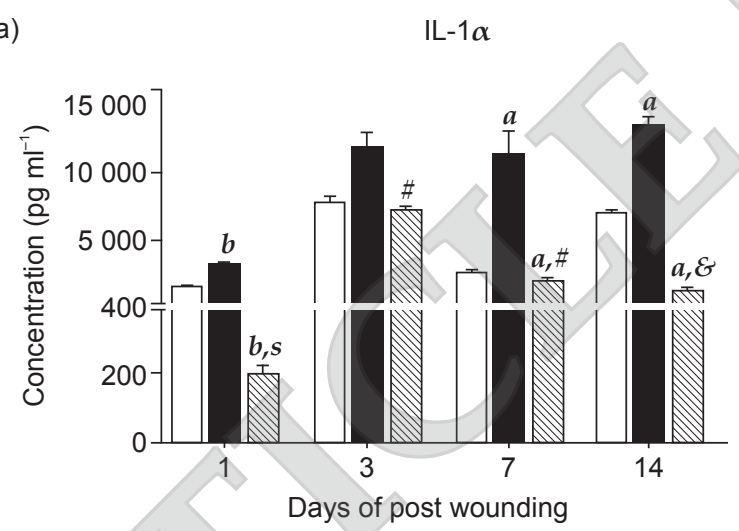

(c)

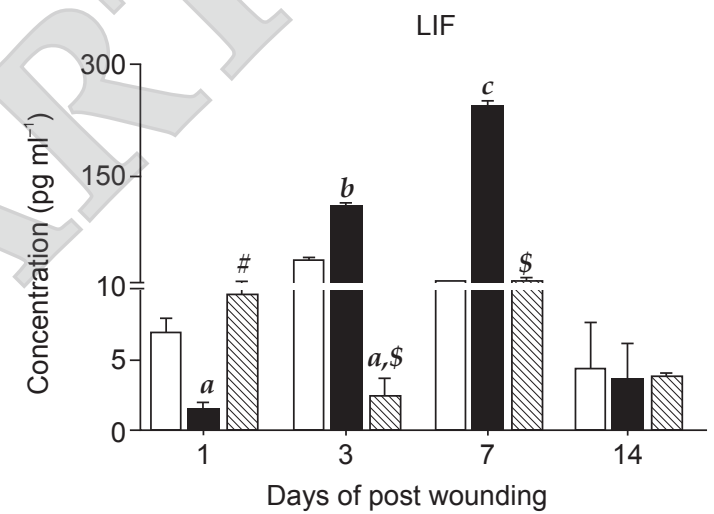

modulate postinfection inflammation and tissue lesions (Fan et al., 2021). However, overexpression of these biomolecules in the wounds of diabetic patients may amplify tissue permeability and leucocyte intrusion, leading to chronic inflammation in the surrounding normal skin and subsequently hindering wound recovery (Fan et al., 2021). Similarly, significant reductions in MCP-1 were observed on day $3(p<0.001)$ compared to those in the T2D control (Figure 6b). MCP-3 has been reported to be a negative regulator of cutaneous inflammation, and its upregulation has been correlated with various inflammatory conditions, such as infection, the tumour microenvironment, and cardiovascular disease (Ford et al., 2019). Our data showed that MCP-3 production was reduced by the TRF on day $3(p<0.05)$, days $7(p<0.01)$ and $14(p<0.05)$ compared to the T2D control (Figure $6 c$ ). However, treatment with the TRF significantly $(p<0.05)$ increased MIP$1 \alpha$ on days 1,3 and 7 compared to that in the T2D control (Figure 6d). This chemokine is often found to be increased in foot ulcer patients (Van Asten et al., 2017). Additionally, MIP-2 was significantly increased on day $1(p<0.05)$, day $7(p<0.01)$, and day $14(p<0.05)$ compared to those in the T2D control (Figure 6e). (b)

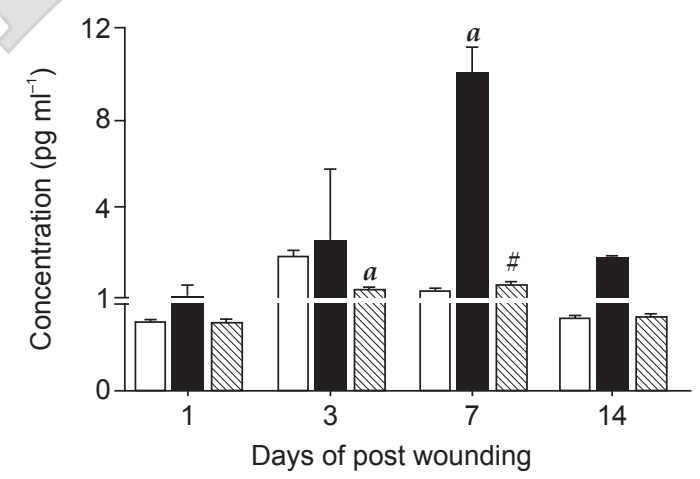

(d)

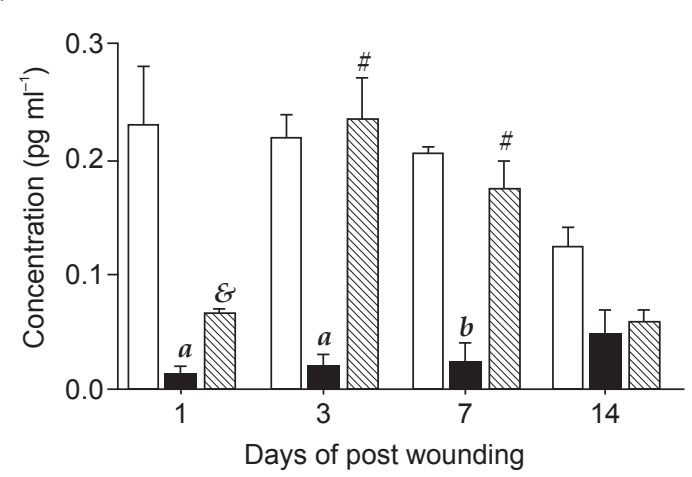

Normal control

T2D control

T2D+TRF

Figure 5. (a-c) Changes in proinflammatory, and (d) anti-inflammatory cytokines in wound tissues in response to TRF. The data are the mean \pm $\operatorname{SEM}(n=3)$ and were calculated using two-way ANOVA with Tukey's multiple comparison test. ${ }^{a} \mathrm{p}<0.05,{ }^{b} \mathrm{p}<0.01,{ }^{c} \mathrm{p}<0.001$ vs. the normal control; ${ }^{\#} \mathrm{p}<0.05,{ }^{8} \mathrm{p}<0.01,{ }^{s} \mathrm{p}<0.001$ vs. the T2D control. 
(a)

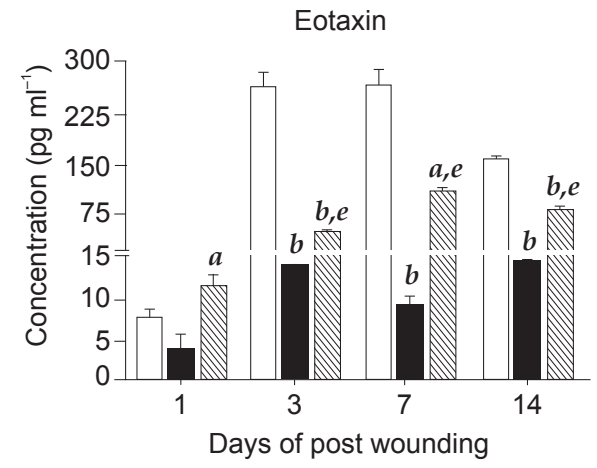

(c)

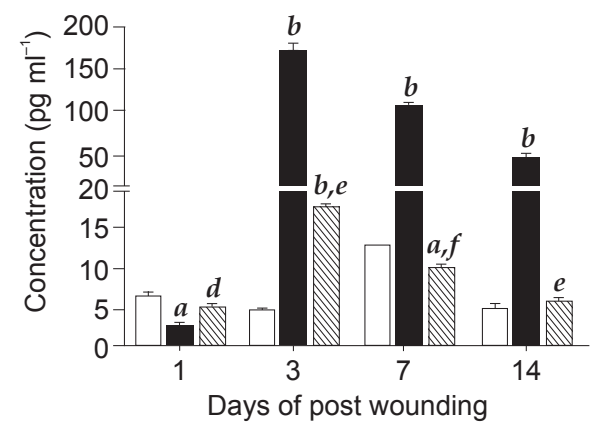

(e)

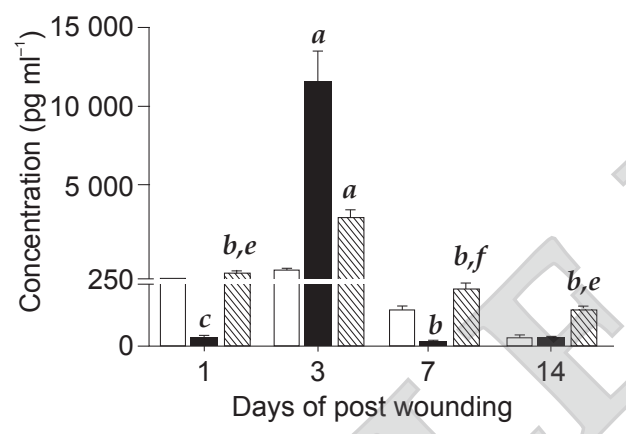

(g)

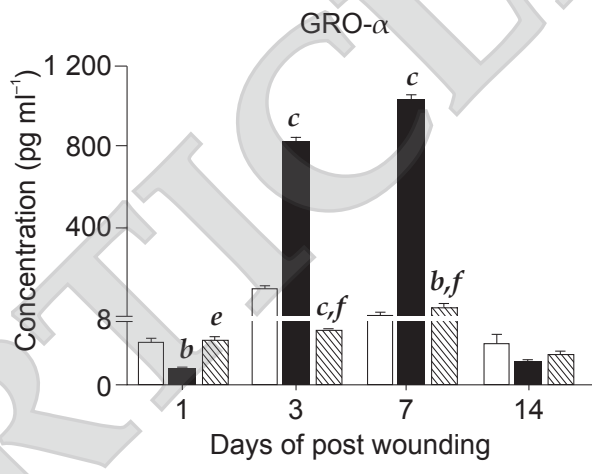

(i)

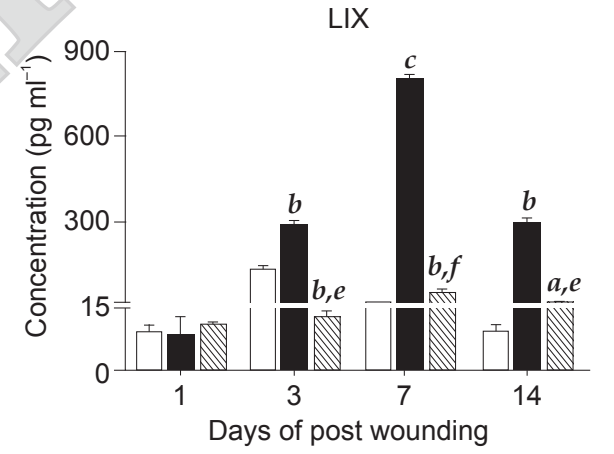

(b)

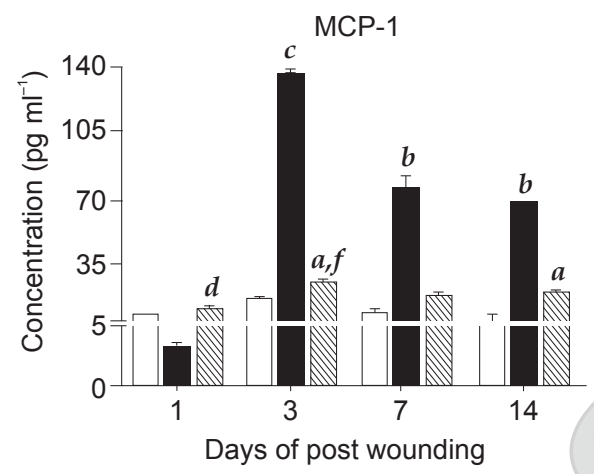

(d)

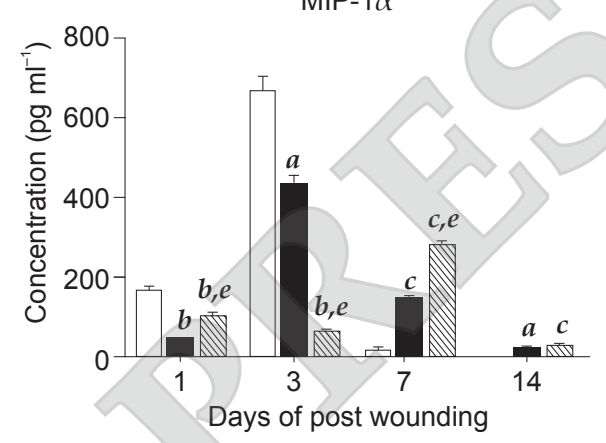

(f)

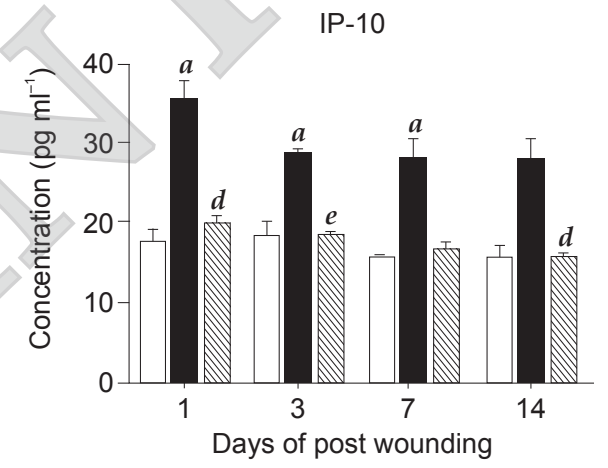

(h)

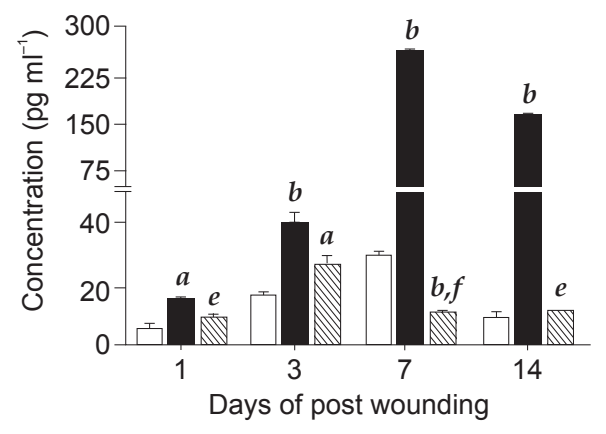

Figure 6. Changes in chemokines in skin wound tissues in response to TRF. The data are the mean $\pm S E M(n=3)$ and were calculated using two-way ANOVA with Tukey's multiple comparison test. ${ }^{a} \mathrm{p}<0.05,{ }^{b} \mathrm{p}<0.01,{ }^{c} \mathrm{p}<0.001,{ }^{d} \mathrm{p}<0.0001$ vs. the normal control; ${ }^{e} \mathrm{p}<0.05,{ }^{f} \mathrm{p}<0.01$ vs. the T2D control. 
Moreover, the inflammatory chemokine IP-10 has been reported to be increased in diabetic patients due to inflammation induced by oxidative stress (Fatehi et al., 2015). TRF treatment significantly reduced IP-10 $(p<0.05)$ on day 3 compared to that in the T2D control (Figure 6f). Higher GRO- $\alpha$ production was observed on days $3(p<0.001)$ and $7(p<0.001)$ in T2D controls than in normal controls (Figure $6 g$ ). Interestingly, a significant reduction was observed in TRF-treated wounds on days $1(p<0.05), 3(p<0.01)$ and $7(p<0.01)$ compared to diabetic control wounds.

RANTES and LIX have been reported to be crucially associated with impaired wound healing (Ligi et al., 2016). Low levels of RANTES have been reported to enhance the inflammatory response in venous leg ulcers (VLUs) throughout the healing process in the wound (Ligi et al., 2016). TRF treatment significantly decreased RANTES levels in diabetic mice on day $1(p<0.05)$, day $7(p<0.01)$, and day $14(p<0.05)$ compared to the T2D control (Figure $6 h)$. A significant decrease in LIX was observed in the TRF-treated group on day $3(p<0.05)$, day 7 $(p<0.01)$ and day $14(p<0.05)$ compared to the T2D control (Figure 6i).

Activation of granulocyte and macrophage lineages is initiated by the pleiotropic cytokine GM-CSF (Rho et al., 2015), which triggers the proliferation of monocytes and granulocytes (neutrophils, eosinophils and basophils) (Bhattacharya et al., 2015; Weston et al., 2018). Due to these effects, an imbalance in GM-CSF production/signalling through ERK1/2 and $\mathrm{NF \kappa B}$ activation (Bhattacharya et al., 2015) may lead to harmful inflammatory conditions (Lotfi et al., 2019). Initially, this cytokine was low on day $1(p<0.01)$ and then increased on day $3(p<0.001)$

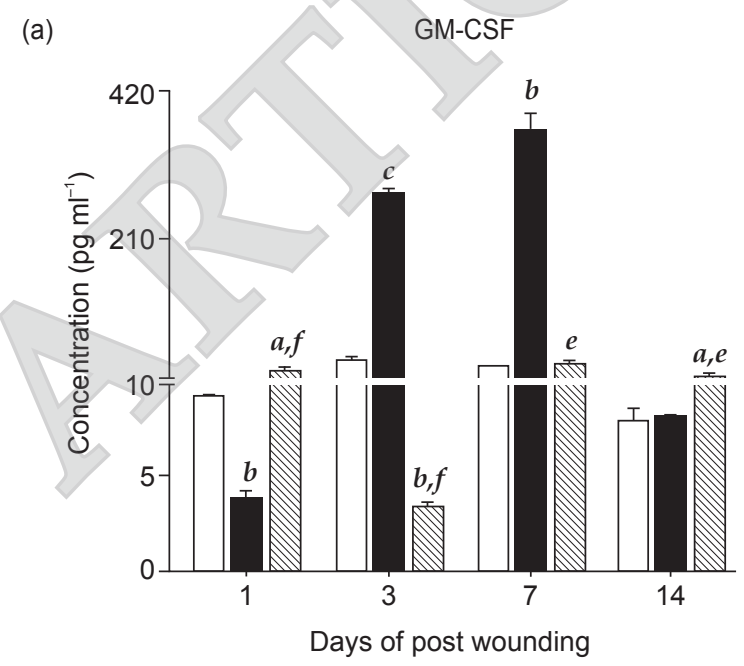

$\square$ Normal control and day $7(p<0.01)$ in T2D controls compared with normal controls (Figure 7a). Treatment with TRF elevated GM-CSF levels on day $1(p<0.01)$, but these levels declined on day $3(p<0.01)$ and increased again on days 7 and $14(p<0.05)$ compared to those of the T2D controls (Figure 7a).

VEGF is known to initiate wound healing and promote expansion of the vascular network (DiPietro, 2016; Zhou et al., 2017) throughout granulation tissue that is essential for providing oxygen, immune cells and nutrients to aid wound healing (Hutchings et al., 2021). This study showed that the production of VEGF in diabetic group was significantly decreased on day $1(p<0.01)$, day $3(p<0.001)$, day $7(p<0.01)$, and day $14(p<0.05)$ compared to that in the normal control (Figure $7 b$ ). However, treatment with the TRF significantly increased VEGF production on day $1 \quad(p<0.05)$, day $3(p<0.01)$, day $7(p<0.05)$ and day $14(p<0.05)$ compared to that in the T2D control. The increase in VEGF production suggests its role in facilitating angiogenesis, thus, promoting the formation of more blood vessels and improving blood flow in the wound area (Johnson and Wilgus, 2014).

There have been several studies on the efficacy of the TRF mediated by a variety of pharmacological activities, including antioxidant (Ahsan et al., 2014), anti-inflammatory and wound healing activities (Elsy et al., 2017). In the present study on T2D diabetic mice, topical application resulted in the acceleration of wound closure, improved re-epithelialisation and increased formation of granulation tissue, which consists of various cells, vascular capillaries and loose connective tissues to fill the injured space (Karim et al., 2021; Tan et al., 2019). Moreover, marked collagen synthesis and deposition with high levels of hydroxyproline

(b)

VEGF-A

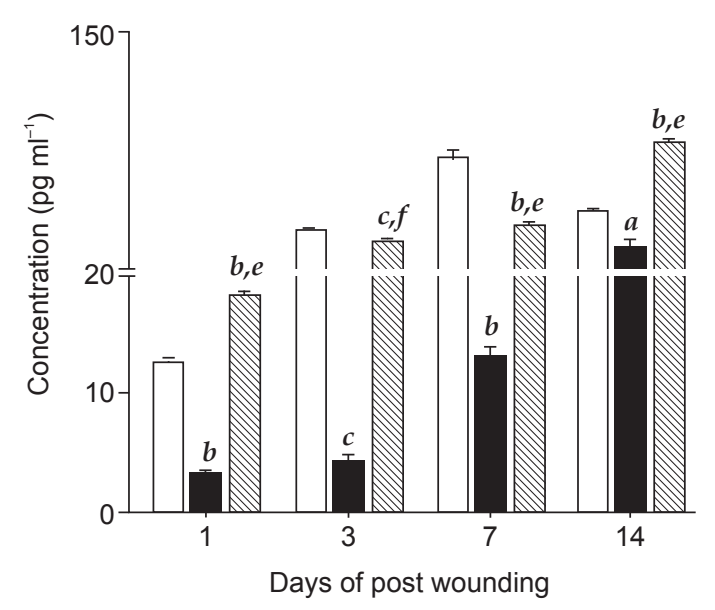

T2D control

$T 2 D+T R F$

Figure 7. Effects of TRF on the levels of (a) GM-CSF, and (b) VEGF-A in skin wound tissues. GM-CSF and VEGF-A levels are represented as the mean $\pm \operatorname{SEM}(n=3)$ and were calculated using two-way ANOVA with Tukey's multiple comparison test. ${ }^{a} \mathrm{p}<0.05,{ }^{b} \mathrm{p}<0.01,{ }^{c} \mathrm{p}<0.001 \mathrm{vs}$. the normal control; ${ }^{e} \mathrm{p}<0.05,{ }^{f} \mathrm{p}<0.01$ vs. the $T 2 D$ control. 


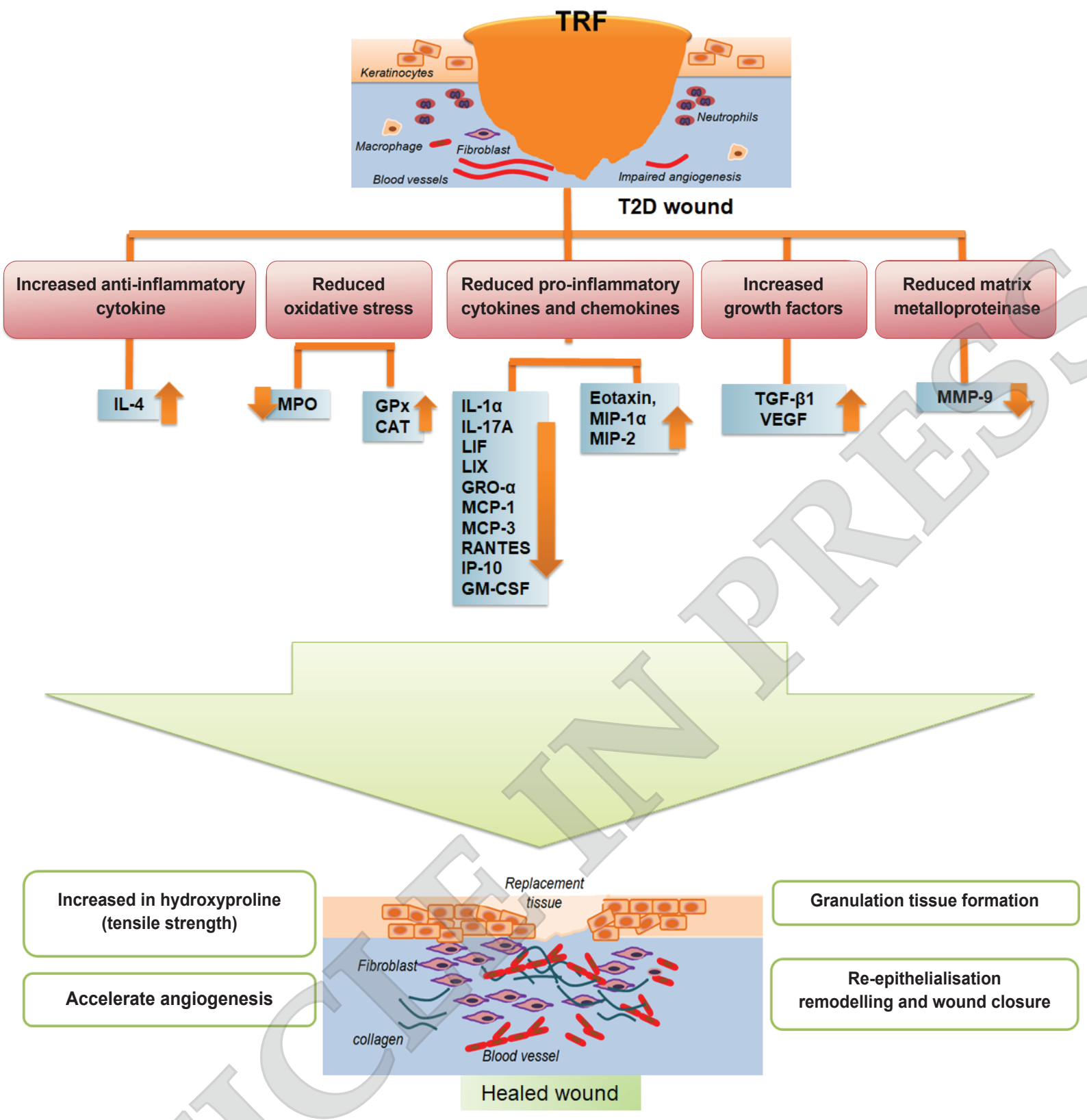

Figure 8. The suggested mechanism by which the TRF enhances wound healing under diabetic conditions.

were observed in TRF-treated diabetic wounds. These results may be due to decreased production of proinflammatory cytokines and metalloproteinases, and increased levels of growth factors released by cells to induce the proliferation and migration of keratinocytes, macrophages, and fibroblasts into the wound space (Rousselle et al., 2019; Tan et al., 2019; Yamakawa and Hayashida, 2019). We also observed increases in antiinflammatory cytokines and antioxidant enzymes at the wound site in diabetic mice. Based on these findings, we proposed a schematic illustration of the potential mechanism by which TRF enables successful healing of wounds in a T2D mouse model (Figure 8) due to the anti-inflammatory and antioxidant potential of the TRF.

\section{CONCLUSION}

Topical application of the TRF promotes wound repair in the cutaneous wounds of $\mathrm{T} 2 \mathrm{D}$ mice. The results of our study demonstrated that topical TRF application accelerated cutaneous wound repair in T2D mice by elevating the levels of antioxidant enzymes such as CAT and GPx and cytokines such as IL-4, reducing MPO, and modulating proinflammatory cytokines, such as IL-1 $\alpha$, IL-17A, and LIF, chemokines (GRO- $\alpha$, MCP-1, -3 , RANTES, IP-10) and GM-CSF in T2D wounds. Moreover, eotaxin, MIP- $1 \alpha,-2$, IL-4, VEGF and TGF- $\beta 1$ levels were elevated in TRF-treated T2D wounds, which accelerated the progression of healing. Thus, the findings of this study suggest the benefits and 
potential use of the TRF as a therapeutic agent to treat cutaneous wounds in T2D patients.

\section{ACKNOWLEDGEMENT}

The authors would like to acknowledge the DirectorGeneral of the MPOB for permission to publish this article.

\section{REFERENCES}

Ahsan, H; Ahad, A; Iqbal, J and Siddiqui, W A (2014). Pharmacological potential of tocotrienols: A review. Nutr. Metab., 11(1): 52.

Alghazeer, R; Alghazir, N; Awayn, N; Ahtiwesh, O and Elgahmasi, S (2018). Biomarkers of oxidative stress and antioxidant defense in patients with type 1 diabetes mellitus. Ibnosina J. Med. Biomed. Sci., 10(6): 198.

Ayuk, S M; Abrahamse, H and Houreld, N N (2016). The role of matrix metalloproteinases in diabetic wound healing in relation to photobiomodulation. J. Diabetes Res., 2016.

Bhattacharya, P; Thiruppathi, M; Elshabrawy, H A; Alharshawi, K; Kumar, P and Prabhakar, B S (2015). GM-CSF: An immune modulatory cytokine that can suppress autoimmunity. Cytokine, 75(2): 261-271.

Brandt, S L; Wang, S; Dejani, N N; Klopfenstein, N; Winfree, S; Filgueiras, L; McCarthy, B P; Territo, P R and Serezani, C H (2018). Excessive localized leukotriene B4 levels dictate poor skin host defense in diabetic mice. JCI Insight, 3(17): e120220.

Burns, B; Jackson, K; Farinas, A; Pollins, A; Bellan, L; Perdikis, G; Kassis, S and Thayer, W (2020). Eosinophil infiltration of burn wounds in young and older burn patients. Burns, 46(5): 1136-1141.

Cano Sanchez, M; Lancel, S; Boulanger, E and Neviere, R (2018). Targeting oxidative stress and mitochondrial dysfunction in the treatment of impaired wound healing: A systematic review. Antioxidants, 7(8): 98.

Chang, Y-C; Soriano, M; Hahn, R A; Casillas, R P; Gordon, M K; Laskin, J D and Gerecke, D R (2018). Expression of cytokines and chemokines in mouse skin treated with sulfur mustard. Toxicol. Appl. Pharmacol., 355: 52-59.

Cheng, H S; Ton, S H; Tan, J B L and Abdul Kadir, K (2017). The ameliorative effects of a tocotrienol-rich fraction on the AGE-RAGE axis and hypertension in high-fat-diet-fed rats with metabolic syndrome. Nutrients, 9(9): 984.

Daemi, A; Lotfi, M; Farahpour, M R; Oryan, A; Ghayour, S J and Sonboli, A(2019). Topical application of Cinnamomum hydroethanolic extract improves wound healing by enhancing re-epithelialization and keratin biosynthesis in streptozotocin-induced diabetic mice. Pharm. Biol., 57(1): 799-806.

Deng, L; Du, C; Song, P; Chen, T; Rui, S; Armstrong, D G and Deng, W (2021). The role of oxidative stress and antioxidants in diabetic wound healing. Oxid. Med. Cell. Longev., 2021. DOI: 10.1155/2021/8852759. eCollection 2021.

DiPietro, L A (2016). Angiogenesis and wound repair: When enough is enough. J. Leukoc. Biol., 100(5): 979-984.

Dwivedi, D; Dwivedi, M; Malviya, S and Singh, V (2017). Evaluation of wound healing, anti-microbial and antioxidant potential of Pongamia pinnata in wistar rats. J. Tradit. Complement. Med., 7(1): 79-85.

Elsy, B; Khan, A A and Maheshwari, V (2017). Effect of co-administration of vitamin $\mathrm{E}$ isoforms $\mathrm{d}-\alpha-$ tocopherol and $\mathrm{d}-\delta$-tocotrienol rich fraction on the healing of skin wounds in diabetic rats. Int. J. Biomed. Eng. Clin. Sci., 3(5): 52-62.

Fan, S L; Lin, J A; Chen, S Y; Lin, J H; Lin, H T; Chen, Y Y and Yen, G C (2021). Effects of Hsiantsao (Mesona procumbens Hemsl.) extracts and its polysaccharides on the promotion of wound healing under diabetes-like conditions. Food and Funct., 12(1): 119-132.

Fatehi, F; Hassanshahi, G; Hosseini, S E; Zade, A S and Taghavi, M M (2015). Systemic effect of Angipars on regulation of wound healing is mediated by CXC in diabetes. Trop. J. Pharm. Res., 14(1): 79-85.

Ferdous, M; Sonam, C R; Mudi, S R; Ali, M; Jasmin, S; Fariduddin, M; Alam, S M K; Arslan, M I and Biswas, S K (2020). Expression of neutrophil elastase and myeloperoxidase mRNA in patients with newly diagnosed type 2 diabetes mellitus. Diabetes Metab. Syndr.: Clin. Res. Rev., 14(2): 83-85.

Fields, J K; Günther, S and Sundberg, E J (2019). Structural basis of IL-1 family cytokine signaling. Front. Immunol., 10: 1412.

Ford, J; Hughson, A; Lim, K; Bardina, S V; Lu, W; Charo, I F; Lim, J K and Fowell, D J (2019). CCL7 is a negative regulator of cutaneous inflammation following Leishmania major infection. Front. Immunol., 9: 3063. 
Hasan, Z A A; Idris, Z; Gani, S and Basri, M (2018). In vitro safety evaluation of palm tocotrienol-rich fraction nanoemulsions for topical application. J. Oil Palm Res., 30: 150-162.

Hadian, Y; Bagood, M D; Dahle, S E; Sood, A and Isseroff, R R (2019). Interleukin-17: Potential target for chronic wounds. Mediat. Inflamm., 2019. DOI: $10.1155 / 2019 / 1297675$.

Hemmati, A A; Larki-Harchegani, A; Shahbib, S; Jalali, A; Rezaei, A and Housmand, G (2018). Wound healing property of milk in full thickness wound model of rabbit. Int. J. Surg., 54: 133-140.

Hutchings, G; Kruszyna, Ł; Nawrocki, M J; Strauss, E; Bryl, R; Spaczyńska, J; Perek, B; Jemielity, M; Mozdziak, P; Kempisty, B; Nowicki, M and Krasiński, Z (2021). Molecular mechanisms associated with ROS-dependent angiogenesis in lower extremity artery disease. Antioxidants, 10(5): 735.

Ighodaro, O and Akinloye, O (2018). First line defence antioxidants-superoxide dismutase (SOD), catalase (CAT) and glutathione peroxidase (GPX): Their fundamental role in the entire antioxidant defence grid. Alexandria J. Med., 54(4): 287-293.

Johnson, K E and Wilgus, T A (2014). Vascular endothelial growth factor and angiogenesis in the regulation of cutaneous wound repair. Adv. Wound Care, 3(10): 647-661.

Jones, J I; Nguyen, T T; Peng, Z and Chang, M (2019). Targeting MMP-9 in diabetic foot ulcers. Pharmaceuticals, 12(2): 79.

Karim, S; AlKreathy, H M; Ahmad, A and Khan, M I (2021). Effects of methanolic extract basedgel from Saudi-pomegranate (Punica granatum L.) peels with enhanced in vivo healing potential on excision wounds in diabetic rats. Front. Pharmacol., 12: 1337 .

Katsuhiro, M; Teoh, S H; Yamashiro, H; Shinohara, M; Fatchiyah, F; Ohta, T and Yamada, T (2018). Effects on glycemic control in impaired wound healing in Spontaneously Diabetic Torii (SDT) fatty rats. Med. Arch., 72(1): 4.

Khan, A A; Alsahli, M A and Rahmani, A H (2018). Myeloperoxidase as an active disease biomarker: Recent biochemical and pathological perspectives. Med. Sci., 6(2): 33.

Khor, S C; Wan Ngah, W Z; Mohd Yusof, Y A; Abdul Karim, N and Makpol, S (2017). Tocotrienol- rich fraction ameliorates antioxidant defense mechanisms and improves replicative senescenceassociated oxidative stress in human myoblasts. Oxid. Med. Cell Longev., 2017.

Kurahashi, T and Fujii, J (2015). Roles of antioxidative enzymes in wound healing. J. Dev. Biol., 3(2): 57-70.

Liarte, S; Bernabé-García, Á and Nicolás, F J (2020). Role of TGF-in skin chronic wounds: A keratinocyte perspective. Cells, 9(2): 306.

Ligi, D; Mosti, G; Croce, L; Raffetto, J D and Mannello, F (2016). Chronic venous disease-Part I: Inflammatory biomarkers in wound healing. Biochim Biophys Acta-Mol. Basis. Dis., 1862(10): 19641974.

Lin, T S; Abd Latiff, A; Abd Hamid, N A; Wan Ngah, W Z and Mazlan, M (2012). Evaluation of topical tocopherol cream on cutaneous wound healing in streptozotocin-induced diabetic rats. Evid. Based Complement. Alternat. Med., 2012. DOI: $10.1155 / 2012$ / 491027.

Lotfi, N; Thome, R; Rezaei, N; Zhang, G X; Rezaei, N; Rostami, A and Esmaeil, N (2019). Roles of GMCSF in the pathogenesis of autoimmune diseases: An update. Front. Immunol., 10: 1265.

Manzuoerh, R; Farahpour, M R; Oryan, A and Sonboli, A (2019). Effectiveness of topical administration of Anethum graveolens essential oil on MRSA-infected wounds. Biomed. Pharmacother., 109: 1650-1658.

Matough, F A; Budin, S B; Hamid, Z A; AbdulRahman, M; Al-Wahaibi, $\mathrm{N}$ and Mohammed, J (2014). Tocotrienol-rich fraction from palm oil prevents oxidative damage in diabetic rats. Sultan Qaboos Univ. Med. J., 14(1): e95.

Musalmah, M; Nizrana, M; Fairuz, A; NoorAini, A; Azian, A; Gapor, M and Ngah, W W (2005). Comparative effects of palm vitamin $\mathrm{E}$ and $\alpha$-tocopherol on healing and wound tissue antioxidant enzyme levels in diabetic rats. Lipids, 40(6): 575-580.

Nor Azman, N H E; Goon, J A; Abdul Ghani, S M; Hamid, Z and Wan Ngah, W Z (2018). Comparing palm oil, tocotrienol-rich fraction and $\alpha$-tocopherol supplementation on the antioxidant levels of older adults. Antioxidants, 7(6): 74 .

Okonkwo, U A and DiPietro, L A (2017). Diabetes and wound angiogenesis. Int. J. Mol. Sci., 18(7): 1419. 
Peiseler, M and Kubes, P (2019). More friend than foe: The emerging role of neutrophils in tissue repair. J. Clin. Invest., 129(7): 2629-2639.

Raziyeva, K; Kim, Y; Zharkinbekov, Z; Kassymbek, K; Jimi, S and Saparov, A (2021). Immunology of acute and chronic wound healing. Biomolecules, 11(5): 700 .

Rho, C R; Park, Mi-Y and Kang, S (2015). Effects of granulocyte-macrophage colony-stimulating (GM-CSF) factor on corneal epithelial cells in corneal wound healing model. PLOS ONE, 10(9): e0138020.

Ridiandries, A; Tan, J and Bursill, C A (2018). The role of chemokines in wound healing. Int. J. Mol. Sci., 19(10): 3217.

Rodrigues, M; Kosaric, N; Bonham, C A and Gurtner, G C (2019). Wound healing: A cellular perspective. Physiol. Rev., 99(1): 665-706.

Rousselle, P; Braye, F and Dayan, G (2019). Reepithelialization of adult skin wounds: Cellular mechanisms and therapeutic strategies. Adv. Drug Deliv. Rev., 146: 344-365.

Serra, M B; Barroso, W A; da Silva, N N; Silva, S D N; Borges, A C R; Abreu, I C and Borges, M O D R (2017). From inflammation to current and alternative therapies involved in wound healing. Int. J. Inflam., 2017. DOI: $10.1155 / 2017 / 3406215$.

Shahidi, F and De Camargo, A C (2016). Tocopherols and tocotrienols in common and emerging dietary sources: Occurrence, applications and health benefits. Int. J. Mol. Sci., 17(10): 1745.

Shahrim, Z; Omar, Z; Zainal, Z and Hasan, Z A A (2016). Palm tocotrienol: A good antioxidant for skin wound healing. Palm Oil Developments, 64: 1419.

Shahrim, Z; Makpol, S; Tan, G C and Azizul Hasan, Z A (2019). Clinical dermatology: Topical application of palm tocotrienol enhances cutaneous wound healing in diabetes. Proc. of the 2019 International Palm Oil Congress - Oleo \& Specialty Chemicals Conference. $\mathrm{MPOB}$, Bangi.

Sokol, C L and Luster, A D (2015). The chemokine system in innate immunity. Cold Spring Harb. Perspect. Biol., 7(5): a016303.

Strang, H; Kaul, A; Parikh, U; Masri, L; Saravanan, S; Li, H; Miao, Q and Balaji, S (2020). Wound Healing, Tissue Repair, and Regeneration in Diabetes. Academic Press. p. 197-235.
Tan, W S; Arulselvan, P; Ng, S F; Taib, C N M; Sarian, M N and Fakurazi, S (2019). Improvement of diabetic wound healing by topical application of Vicenin-2 hydrocolloid film on Sprague Dawley rats. BMC Complement. Altern. Med., 19(1): 1-16.

Thangavel, P; Ramachandran, B; Chakraborty, S; Kannan, R; Lonchin, S and Muthuvijayan, V (2017). Accelerated healing of diabetic wounds treated with L-glutamic acid loaded hydrogels through enhanced collagen deposition and angiogenesis: An in vivo study. Sci. Rep., 7(1): 1-15.

Thangavel, P; Kannan, R; Ramachandran, B; Moorthy, G; Suguna, L and Muthuvijayan, V (2018). Development of reduced graphene oxide (rGO)isabgol nanocomposite dressings for enhanced vascularization and accelerated wound healing in normal and diabetic rats. J. Colloid Interface Sci., 517: 251-264.

Tsalamandris, S; Antonopoulos, A S; Oikonomou, E; Papamikroulis, G A; Vogiatzi, G; Papaioannou, S; Deftereos, S and Tousoulis, D (2019). The role of inflammation in diabetes: Current concepts and future perspectives. Eur. Cardiol., 14(1): 50.

Van Asten, S A; Nichols, A; La Fontaine, J; Bhavan, K; Peters, E J and Lavery, L A (2017). The value of inflammatory markers to diagnose and monitor diabetic foot osteomyelitis. Int. Wound J., 14(1): 4045 .

Wang, L; Qin, W; Zhou, Y; Chen, B; Zhao, X; Zhao, H; Mi, E; Mi, E; Wang, Q and Ning, J (2017). Transforming growth factor $\beta$ plays an important role in enhancing wound healing by topical application of Povidone-iodine. Sci. Rep., 7(1): 991.

Weston, B R; Li, L and Tyson, J J (2018). Mathematical analysis of cytokine-induced differentiation of granulocyte-monocyte progenitor cells. Front. Immunol., 9: 2048.

Xiao, T; Yan, Z; Xiao, S and Xia, Y (2020). Proinflammatory cytokines regulate epidermal stem cells in wound epithelialization. Stem Cell Res. Ther., 11(1): 1-9.

Yap, W N (2018). Tocotrienol-rich fraction attenuates UV-induced inflammaging: A bench to bedside study. J. Cosmet. Dermatol., 17(3): 555-565.

Yamakawa, S and Hayashida, K (2019). Advances in surgical applications of growth factors for wound healing. Burns and Trauma, 7. DOI: 10.1186/s41038019-0148-1.

Yuan, Y; Das, S K and Li, M (2018). Vitamin 
$\mathrm{D}$ ameliorates impaired wound healing in streptozotocin-induced diabetic mice by suppressing NF-kB-mediated inflammatory genes. Biosci. Rep., 38(2): BSR20171294.

Zadeh Gharaboghaz, M N; Farahpour, M R and Saghaie, S (2020). Topical co-administration of Teucrium polium hydroethanolic extract and Aloe vera gel triggered wound healing by accelerating cell proliferation in diabetic mouse model. Biomed. Pharmacother, 127: 110189.

Zhao, R; Liang, H; Clarke, E; Jackson, C and Xue, M
(2016). Inflammation in chronic wounds. Int. J. Mol. Sci., 17(12): 2085.

Zhou, J; Ni, M; Liu, X; Ren, Z and Zheng, Z (2017). Curcumol promotes vascular endothelial growth factor (VEGF)-mediated diabetic wound healing in streptozotocin-induced hyperglycemic rats. Med. Sci. Monit., 23: 555-562.

Zheng, Y; Ley, S H and Hu, F B (2018), Global aetiology and epidemiology of type 2 diabetes mellitus and its complications. Nat. Rev. Endocrinol., 14(2): 88-98. 